NBER WORKING PAPER SERIES

THE INEFFICIENCY OF MARGINAL-COST

PRICING AND THE APPARENT RIGIDITY OF PRICES

Robert E. Hall

Working Paper No. 1347

NATIONAL BUREAU OF ECONOMIC RESEARCH

1050 Massachusetts Avenue

Cambridge, MA 02138

May 1984

I am grateful to Alexander Rawls and Jonathan Feinstein for assistance and to Timothy Bresnahan, John Haltiwanger, Michael Magill, A. Mitchell Polinsky, William Rogerson, and Eytan Sheshinsky for helpful discussions. The research reported here is part of the NBER's research program in Economic Fluctuations. Any opinions expressed are those of the author and not those of the National Bureau of Economic Research. 
NBER Working Paper \#1347

May 1984

\section{The Inefficiency of Marginal-Cost Pricing and the Apparent Rigidity of Prices}

\section{ABSTRACT}

Under conditions of natural monopoly, private contracts or government regulation may attempt to avoid inefficiency by setting up a pricing formula. Once the capital stock is chosen, the right price to charge the buyer is marginal cost. But the point of this paper is that marginal-cost pricing provides the wrong incentives for the choice of the capital stock by the seller. If the seller can achieve a high price by deliberately under-investing and driving up marginal cost, there will be a systematic tendency toward too smali a capital stock. One type of contract or regulatory policy that avoids this problem charges marginal cost to each buyer, but provides a revenue to the seller that is equal to long-run unit cost, not short-run marginal cost. Such a contract or policy will make the price, in the sense of the revenue of the seller per unit of output, appear to be unresponsive to market conditions.

Robert E. Hall

Herbert Hoover Memorial Building

Stanford University

Stanford, California 94305

(415) $497-2215$ 
Setting price equal to marginal cost can be inefficient. Marginal cost prices provide the correct allocation of the output from a fixed amount of capital, but may provide the wrong incentives for capital accumulation. When a seller receives marginal cost, it has an incentive to raise marginal cost by investing too little. In cases of natural monopoly, certain important economic institutions have arisen to prevent inefficient exploitation of monopoly power. These institutions involve long-term contracts or government regulation. This paper shows that a contract or regulatory procedure granting a seller a price equal to its own marginal cost is inefficient. On the other hand, marginal cost is the appropriate price to charge purchasers.

Contracts can circumvent the conflict between the need for efficient allocation of output among buyers, which seems to call for marginal-cost pricing, and the need for efficient investment, which excludes marginal-cost pricing. The fully efficient contract charges marginal cost to each purchaser, but provides stable revenue to the seller, so the seller cannot improve profit by deliberately creating a shortage of capacity. When demand is strong and all customers are paying premium prices, the excess revenue is returned to the customers as lump-sum rebates, instead of flowing to the firm. 
A wide variety of contracts of this type can bring both kinds of efficiency--allocation of output and approprsate investment. They all prevent the seller from profiting from a shortage of capital, but otherwise do not limit the relation between output and revenue. But I argue that one member of the class of fully efficient contracts has some extra advantages and fits the facts about output and revenue. Under this contract, revenue is strictly proportional to output, or, to put it another way, the "price," in the sense of revenue per unit of output, is predetermined by the contract ipossibly it is indexed to observed input costs). Frice rigidity is a feature of the contract.

Earlier writers, notably Arthur okun (1975, 1981) have commented upon the tendency for long-term relations to stabilize unit revenue, but have invoked alternative principles to explain the stability. Some of the principles are outside the domain of economics, and others, especially those relying on search and information, are yet to be fully developed. The principle studied here is a straightforward economic one.

The sense in which prices are rigid in the model of this paper has no direct keynesian implications; that is, price rigidity does not lead to disequilibrium in product markets. Efficient allocations of output do not admit an interpretation of disequilibrium. In this respect, the arqument developed in this paper parallels the conclusion reached in the literature on labor contracts (for citations, see Hall, 1980). Contracts can 
stabilize wages without necessarily creating an inefficient allocation of labor.

In another respect, however, the argument of this paper does have important macroeconomic, and perhaps even keynesian, implications. Frices are thought to be important signals about the current state of the economy. For example, the performance of labor contracts is much better if they can be indexed to the prices at which goods are actually bought and sold. But if government price indexes report unit revenue, and unit revenue is stabilized for the reason laid out here, then the value of those price indexes in contingent contracts is much reduced.

The inefficiency of marginal-cost pricing is not completely unknown in the literature on efficient regulation. In Alfred Kiahn's two-volume treatise, The Economics of Fegulation (1970), there are two long chapters on the virtues of marginal-cost pricing. In a single footnote fiahn notes the investment disincentive ( .106 , note 52):

\footnotetext{
ilie public utility rates were free to fluctuate like purely competitive rates over the cycle, it would in principle be necessary for regulatory commissions to play a much more active role than they now need to in the investment decision process-specifically, to compel companies to expand capacity when necessary. Frivate managements would have a strong temptation to delay capacity expansion in times of strong demand, hoping instead to enjoy the high profits resulting from the high prices required to ration customers.
} 
kahn mentions earlier work of James Bonbright (1961), which contains a brief statement of the point and cites Bruce knight (1930), as the originator. But knight's paper does not really distinguish between the obvious problem of letting a monopoly utility set its own price unilaterally and the more subtle problem of a rule requiring price to equal marginal cost. In Jacques Dreze's review of the contributions of French applied economists (1964), there is a brief discussion of the incentives facing the firm subject to marginal-cost pricing, but it reaches the incorrect conclusion that private and social optimality coincide. Alan Walters (1968) monograph on the economics of public roads also notes, briefly, the problem of the inappropriate incentives for investment under marginal cost pricing, but all of his analysis deals with a public agency that avoids the problem by adopting consumer surplus rather than revenue as the positive item in its objective function. Ás far as I can determine, the outpouring of wort on peat load pricing

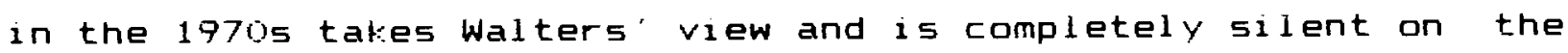
issue of investment incentives. 


\section{Evidence on price rigidity}

Empirical studies for the United States are almost unanimous in finding that fluctuations in prices and output are not movements along a marginal cost schedule. At the aggregate level, this was the consensus of the Eckstein volume (1971) and a good deal of later work in the same vein. In most of this work, the issue is posed as one of finding demand effects in an equation with price as the left-hand variable and cost indexes as the major righthand variables. The interpretation in terms of movements along a marginal cost schedule is mine and not the original authors'. As a rough guide, the elasticity of price with respect to the utilization rate (output-capital ratio) should be about one-half if the elasticity of output with respect to variable inputs is two-thirds. Though most studies find slightly positive demand effects, they are never close to an elasticity of a half.

Figure 1 presents data on prices relative to costs for the aggregate U.S. economy and Figure 2 does the same for one key industry producing a major intermediate product, steel. The aggregate price is the implicit deflator for GNF in the National Income and Froduct Accounts and the corresponding cosi index is the Bureau of Labor Statistics' index of compensation per employee-hour. Both are expressed as indexes with trends removed.

The expansion of output from 1954 to 1955 was accompanied by a modest increase in prices relative to costs. Then, as output 
Figure 1. Output and the price-cost ratio for the U.S. economy

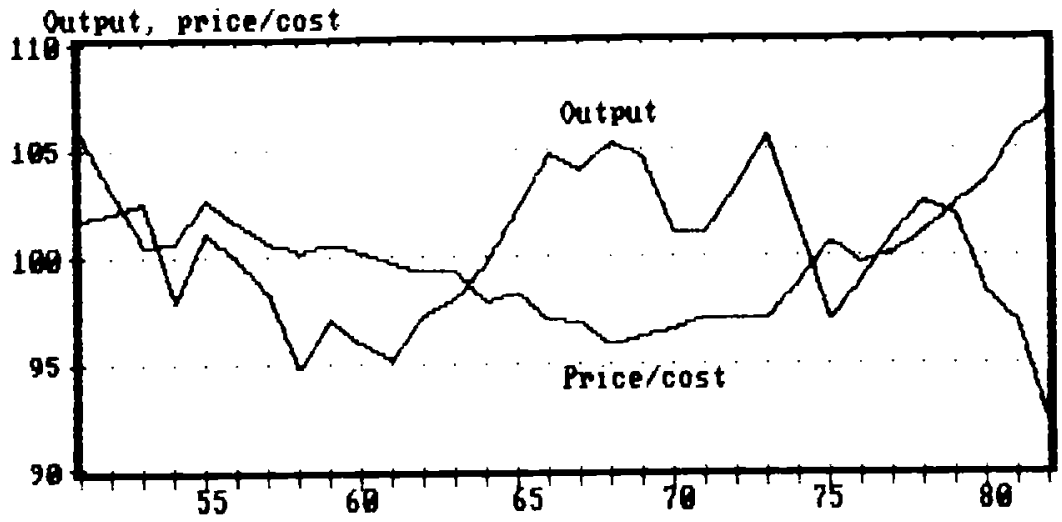

Sources: U.S. price is the implicit deflator for GNF, U.S. National Income and Product Accounts. Cost is Bureau of Labor Statistics, compensation per employee hour, private nonfarm economy. Output is real GNF, U.S. NIFA.

Figure 2. Output and the price-cost ratio in the steel industry

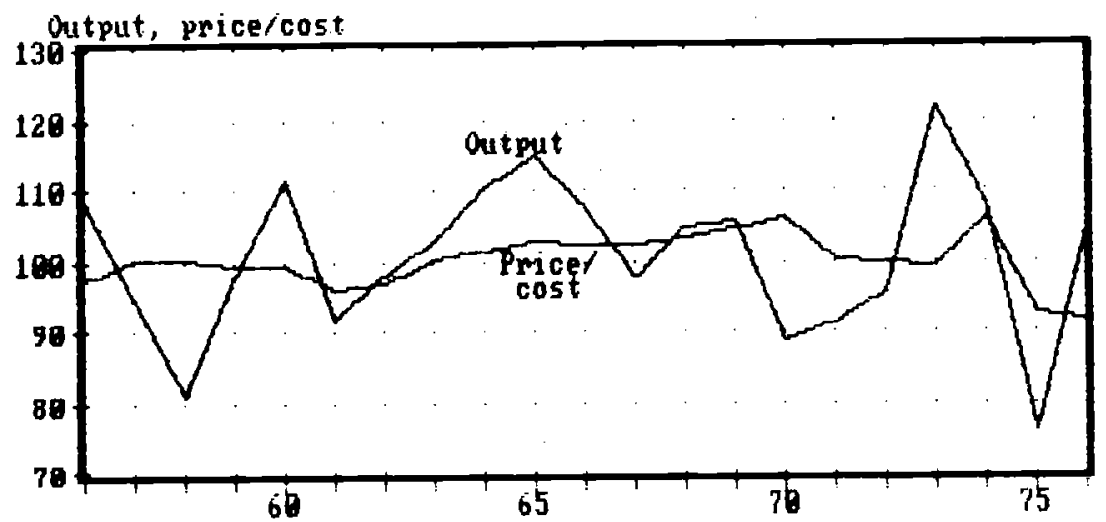

Sources: Steel price is average realized U.S. producers prices of cold-rolled carbon steel sheet, Table A-S. P. 159 in Crandall (1981). Cost is U.S. production costs for cold-rolled sheet, Table A-1S, P. 172. Output is domestic shipments of cold-rolled sheet, Table A-2, P. 158 . 
fell to its troughs in 1958 and 1961 , prices fell somewhat. When output began its spectacular long rise from 1961 to 1966 , prices continued to decline relative to costs. The fall in output from 1969 to 1971 saw a small increase in the price-cost ratio. In the later 1970s, the movement of prices is influenced by energy costs, which are not considered here. Even so, there is no sign of movement along an upward-sloping marginal cost schedule. In 1982, when output fell to its lowest point in the entire period, prices continued to rise relative to costs.

Data for the steel industry are drawn from Fobert Crandali's (1981) study of the economics of steel. Frice is measured as revenue divided by output for a single homogeneous product, coldrolled sheet. Cost is a detailed index of all components of steel costs. Again, there is no systematic tendency for price to rise relative to cost in booms or fall in periods of low output. From 1956 to 1958 , steel output fell by 23 percent, while price rose a little relative to cost. From a trough in 1970 to a peak: in 1973 , steel output rose by 44 percent, yet the price fell significantly relative to cost.

These data strongly support the hypothesis that prices are closely linked to factor costs and hardly linked to short-run marginal cost at all. The rest of the paper investigates why contracts might have exactly this feature and yet provide the efficient allocation of output and the efficient level of the capital stock. 


\section{Contracts and allocational efficiency}

As a general matter, I will be looking at a situation where one producer sells output to $N$ purchasers. The terms of the transactions are governed by $N$ separate bilateral sales contracts. Events occur in the following order: At contract time, the terms are set. At investment time, the firm determines the level of capital to maximize expected profit under the contract. At production time, the output is produced and delivered to the purchasers. Buyer i's need for the output is perturbed by a random variable, $x_{1}$, whose value is not known at all at contract time. At investment time, the producer has imperfect information about the likely demand, but this information is not verifiable and the contract cannot be made contingent on it. The advance information is described by a scalar random variable, u. At production time, the buyers learn their $\times: 5$, but again, they cannot be verified by the seller. The quantity delivered to purchaser i is qu. The total delivered to all purchasers is $Q$. Buyer $i$ derives a benefit, $V_{1}^{1}\left(q_{1}, x_{1}\right)$, from receiving q.. The producer incurs short-run variable costs of $C(Q, K, w)$ plus capital costs of $r k . \quad r$ is the capital stock chosen by the producer at investment time. The wage, w, and the price of capital, $r$, become known after the contracts are signed but before the capital decision is made.

For convenience, I introduce unnecessarily strong assumptions 
For convenience, I introduce unnecessarily strong assumptions about $V^{*}$ and $C$ :

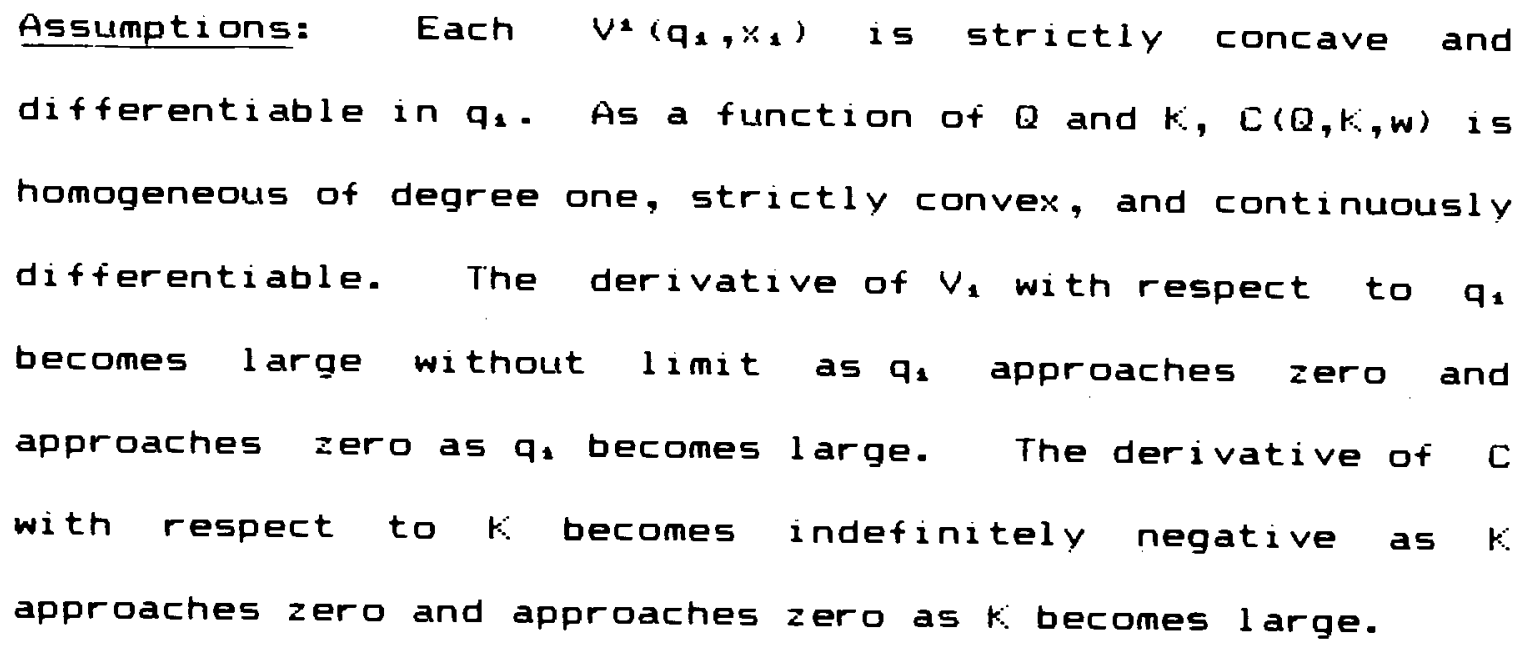

The goal of the parties is to set up a procedure to deliver the efficient quantity to each purchaser. The first concept of efficiency used here is

Definition. An allocation of output, $4 ., \ldots$. q, is outputefficient if it maximizes

$=v_{1}\left(q_{1}, x_{1}\right)-C\left(\Sigma_{1}, k, w\right)$

Note that output efficiency is a property of the allocation ex post, after the demand shifts and factor prices become finown.

The following obvious result will be used extensivelv in the sequel : 
Theorem 1. There exists a unique output-efficient allocation, characterized by

$$
\frac{\partial V_{1}}{\partial Q_{1}}=\frac{\partial C}{\partial Q}
$$

That is, whatever capital stock has been chosen by the producer, the marginal benefit of output to each purchaser should equal short-run marginal cost at that capital stock.

The second concept of efficiency is

Definition. k is capital-efficient if it maximizes

$$
E\left[E V_{1}\left(q_{1}, x_{1}\right)-C\left(\Sigma q_{1}, k_{1}, w\right)-r k\right]
$$

where the expectation is over the distribution of $x$ conditional on the information available to the producer at investment time, $u$, and the $q_{1}$ are the output-efficient levels given $k$.

The parallei result for capital efficiency is:

Theorem 2. There is a unique efficient capital stock, and it satisfies

$$
E\left(-\frac{i C_{i}}{i k}=r\right.
$$

The expected marginal reduction in cost associated with an increase in the capital stock should equal the cost of capital. 
In order to achieve the efficient allocation, the parties agree on a contract. A suitable class of contracts lets the buyer pick: the value of $q_{1}$ subject to making a payment to the seller in the amount $F^{1}\left(q_{1}, Q, k, w, r\right)$. The general argument in favor of a contract that has the buyer choose the quantity appears in Hall and Lilien (1979) in the context of the labor market and in Weitzman (1981) in a setting like this one. Eriefly, when one party observes some private information and the other party is affected by nothing but public information, the first party should male the active choice because it internalizes the influence of the private information. 


\section{Contract provisions to provide the efficient capital stock}

What is distinctive and complex about the setup considered in this paper is the investment decision made by the producer after contracts are signed. The total revenue from all its contracts provides an investment incentive to the firm, and the contracts must be designed to provide the right incentive in order to achieve capital efficiency.

There is one minor obstacle to contracting for exact capital efficiency. As a general matter, the information available to the firm at investment time, indexed by $u$, may convey more than just the level of demand. If so, the prohibition of contingencies on $u$ may make it impossible to frame a contract to achieve exact capital efficiency. But if u conveys pure scale effects, then, as I will demonstrate shortly, contracts are available in which efficiency does not require contingencies on u. The following assumptions are sufficient conditions for a capital efficient contract not contingent on $u$ :

\section{Assumptions:}

(A) The demand shifts, $x_{1}$, are scale effects in the sense that $V_{1}\left(q_{1}, x_{1}\right)$ is homogeneous of first degree in $q_{1}$ and $x_{1}$. (B) The preliminary information, $u$, conveys the scale of the $x_{1}$, in the sense that the conditional distribution of $x_{1}$ given $u$ has density $g_{1}\left(x_{1} / u\right) / u$. 
(C) The revenue formula $R(Q, k, w, r)$ is homogeneous of degree one in $Q$ and $K$.

It will turn out to be reasonable to consider contracts in which the quantity choices of the purchasers influence the producer's revenue only through total quantity and not through the vector of quantities chosen separately by each purchaser. In this case, the revenue of the producer is a function $R(Q, k, w, r)$. The producer chooses $k$ to maximize expected profit,

$$
E[F(Q(k, w, r, x), k, w, r)-C(Q, k, w)-r k]
$$

Here I have noted that $Q$ depends on the producer's choice of $k$. because $t$ affects marginal cost, which in turn affects the efficient level of output. The marginal conditions for a maximum of profit are

$$
E\left[\frac{\partial R}{\partial Q} \frac{\partial Q}{\partial K}+\frac{\partial K}{\partial K}-\frac{\partial C}{\partial Q} \frac{\partial Q}{\partial K}-\frac{\partial C}{\partial K}-r\right]=0
$$

Recall that investment efficiency requires $E\left[-\frac{C}{\partial K}-r\right]=0$, so the contracts must satisfy 
Theorem 3. A contract with revenue formula $F(Q, k, w, r)$ provides capital efficiency only if Ex: $\{u\}$

$E\left[\left(\frac{\partial F}{\partial Q}-\frac{\partial C}{\partial Q}\right) \frac{\partial Q}{\partial K}+\frac{\partial F}{\partial K}\right]=0$

Further, if a formula satisfies this condition for $u=1$ and al $1 w$ and $r$, it satisfies it for all $u, w$, and $r$.

This theorem provides a criterion for a capital-efficient revenue formula. Its three terms net to zero in order for the formula to provide the right incentives for capital efficiency. The first two arise because changes in the capital stock change the level of output. The first term is the extra revenue the formula provides for the extra output. The second is the extra cost incurred in producing the output. The third term is the extra revenue the formula may provide for the extra capital. If, for example, the formula provides less compensation for the extra output than its marginal cost, then it must provide an offsetting amount of direct compensation for the capital itself.

The property that a formula achieving capital efficiency at u=1 also achieves it for any value of $u$ means that the formula need not be contingent on the value of $u$, which we assume is not public knowledge. 
The inefficiency of marginal-cost pricing can now be demonstrated. With marginal-cost pricing, the contract specifies a price,

$$
p(k, w, x)=\frac{\Delta C}{B Q}
$$

which is marginal cost. Then revenue is price times quantity,

$$
F(\theta, k, w, r)=p(k, w, x) Q
$$

The derivative of revenue with respect to output is just the price, which equals marginal cost. Therefore the first two terms in the criterion for capital efficiency cancel each other. All that is left is the third term, the derivative of revenue with respect to the capital stock. This must equal zero for capital efficiency. However, with marginal-cost pricing, that derivative is $\frac{j p}{j k}$, which is negative, not zero. The larger is the capital stock, the lower is the price--more capital lowers marginal cost. Frofit maximization cannot bring the firm to the efficient stock. This conclusion is summarized in

Theorem 4. Under marginal-cost pricing, expected profit is a strictly decreasing function of the capital stock, at the efficient capital stock. 
Hesides marginal-cost pricing, two other simple revenue functions deserve mention because they are inefficient. One is to let revenue equal cost

$$
R(Q, K, w, r)=C(Q, K, w)+r K
$$

This revenue function satisfies the marginal conditions for capital efficiency but not the second order conditions. The producer has profit of zero no matter what, and so is indifferent among all levels of k. The purchasers would have to develop some method outside the revenue function to steer the producer to the efficient capitial stock.

Another choice is to make revenue independent of either output or capital. At first, this seems like the right approach. The two parties want the producer to pick the efficient capital stock: so as to minimize the expected cost of producing whatever level of output the purchasers decide to take. Maximising profit might then seem to be equivalent to minimizing cost. Eut the firm influences the level of output through its choice of the capital stock, even though the purchasers have the Linilateral power to choose the amount of output. For constant revenue,

$$
F(Q, r, w, r)=F i o
$$

the criterion $I \subseteq$ 


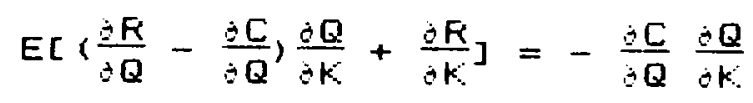

which is unambiguously negative. The firm faces an inappropriate disincentive to invest because it is not rewarded for the cost of producing the extra output stimulated by extra capital.

Though none of the three revenue formulas considered so far provides the right investment incentives, the marginal condition for capital efficiency is not actually very restrictive. Many combinations of rewards for the extra output associated with extra capital, $\frac{\mathrm{F}}{\partial Q} \frac{\partial Q}{\partial K}$, and direct rewards for investment, $\frac{\mathrm{F} i}{\mathrm{k}}$, add up to offset the investment disincentive, $\frac{\dot{\partial} C}{\partial Q} \frac{\partial Q}{a k}$ If the conditions imposed on the revenue formula by output efficiency are not too restrictive, capital efficiency is relatively easy to achieve.

A particularly interesting and simple way to provide the firm with the right incentives is to male revenue a fixed amount, $\$(w, r)$, per linit of output. Then

$$
F(Q, F, w, r)=Q(w, r)
$$

This formula provides no direct reward for investment, but can achieve efficiency by providing sufficientl $v$ strong compensation for output. The marginal condition is

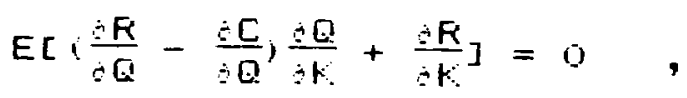


or

$$
\left.E\left[\phi-\frac{\partial C}{\partial Q}\right) \frac{\partial Q}{\partial K}\right]=0 \quad .
$$

Define the random variable $=$ as

$$
\Sigma=\frac{\partial Q}{\partial K} / E\left(\frac{\partial Q}{\partial K}\right)
$$

$z$ is a weight in the sense that its expected value is one. Then the marginal condition can be written as

$$
(w, r)=E\left(z \frac{\partial C}{\Delta Q}\right)
$$

The efficient amount of revenue per unit of output is the weighted expectation of marginal cost. Roughly speaking, unit revenue should be long-run average cost. The roughness comes from the treatment of uncertainty--the weighted average of marginal cost takes exact account of the cost of meeting the producer's commitment to meet variable demand. If the notion of long-run average cost is modified to take account of the cost of the variability, then the principle of setting short-run unit revenue equal to long-run unit cost is an appropriate one. In the related context of peat:-load pricing, Boiteus (1949) showed that the average marginal cost should equai long-run unit cost. The problem faced by the designers of contracts lor by the regulatory is to find a way to give the producer long-run marginal cost while at the same time charging the buyers short- 
run marginal cost. When there are many buyers, a contract form with precisely the right characteristics is available, as the next section will show.

\section{Contracts to provide both output and capital efficiency}

The type of contract considered in this paper is most at home when one producer sells to many buyers. When the buyers have the unilateral power to determine the quantities they take, the producer need not be concerned with the circumstances of each of the many purchasers. Instead, the producer should offer. a standardized contract to each buyer. This section shows that such contracts can provide both output and capital efficiency. key to the functioning of the contracts is the notion that each buyer is small enough so that its purchases do not affect marginal cost. Efficiency is approximate in exactly the same way that the efficiency of competitive equilibrium is approximate-participants are unaware of their small amount of monopsonv power. The standardized contract studied here has the form

$$
\begin{aligned}
& R^{1}\left(q_{1}, Q, k, w, r\right)=A\left(q_{1}, Q, k, w, r\right)+s_{1} E(Q, k, w, r) \\
& \text { with } A(0, G, k, w, r)=0 .
\end{aligned}
$$

Differences among customers are captured by the quantity thev purchase, $q_{1}$, and a scale variable, $s_{1} ;$ in all other respects, 
all customers have the same contract. The scale variables sum to unity: $\Sigma s_{1}=1$. Linearity in the $s_{1}$ means that the producer's revenue is independent of the $5_{1}$. The approximate concept of output efficiency is expressed in

Definition. A contract is output-efficient for a smail purchaser if

$$
A(q+, Q, k, w, r)=q \cdot \frac{\partial L}{\partial Q} \text {. }
$$

That is, the purchaser pays marginal cost for $q_{1}$, but the roie of $q_{1}$ in total output, $Q$, is ignored.

This definition saves some tedious arguments later, none of which is a departure from the same development of the efficiency of competitive equilibrium.

Output efficiency restricts the form of the standardized contract:

Theorem 5. A standardized contract is output-efficient for a small purchaser if and oniy if it can be written in the form

$$
\begin{aligned}
& A\left(q_{1}, 0, f, w, r\right)+ 5, B(Q, f, w, r)= \\
& \qquad\left(q_{1}-5,0\right) \frac{\partial E}{\partial Q}+5, f(Q, f, w, r) ; \\
& F i \text { is an unrestricted function. }
\end{aligned}
$$


Output efficiency requires that the payment made by a single purchaser be a linear function of the quantity purchased. The coefficient of $q_{1}$ must be marginal cost. Again, output efficiency calls for marginal-cost pricing.

In the standardized contract, each purchaser makes a payment, $s_{1} f(0, k, w, r)$, independent of the quantity it purchases. It makes a further payment to the extent its purchase, q1, exceeds its prescribed share of total output, S.Q. Output efficiency requires that the payment for the extra output be at marginai cost, and aiso that the purchaser earn a reward at marginal cost for taking iess than its share.

So much for output efficiency. Capital efficiency involves the total revenue of the producer,

$$
E\left[\left(q_{1}-s_{1}(0) \frac{E}{D}+s_{1} F\right]=F(Q, k, N, r)\right. \text {. }
$$

Thus, the standardized contract imposes no restrictions at ali on the revenue received by the producer. Any function, $F$, satisfying the criterion for capital efficiency,

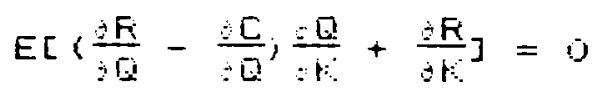

can be inserted inco the standardized contract to maile it simultaneousiv output- and capital-efficient. 
How does the standardized contract for multiple purchasers accomplish its goal? In effect, charging a purchaser only for the departure of its purchase from its share of total output makes the N-1 other purchasers function as a third party to the contract between the purchaser and the seller. When demand is strong, customers face high prices in the allocational sense, but the revenue from those high prices flows to the customers as a group, not to the producer. In this way, the producer does not face the incentive to create chronic shortages by investing in too little capital. Lorne Carmichael (1983) has suggested a parallel contract in the labor market, where the other employees in a firm function as the third party in the contract between the firm and one employee. The potential role of third parties in efficient contracts has been explored extensively in the 1 iterature on incentive compatibility: See Green and Laffont $(1977)$ for a general discussion.

As section $\exists$ of the paper concluded, many different revenue formulas $F(Q, K, w, r)$ can assure capital efficiency. Eut constant unit revenue,

$$
R(Q, K, w, r)=E \neq(w, r)
$$

is a natural and realistic cholce. The standardized contract becomes 


$$
\left(q_{1}-s_{1} Q\right) \frac{\partial C}{\partial Q}+s_{1} Q \phi(w, r)
$$

In words, the purchaser and the producer agree on a normal share of total output. If the purchaser elects to take exactly its normal share, it pays long-run unit cost. Departures from the normal share are priced at current marginal cost. Total revenue from all customers is long-run unit cost times output, and is independent of the capital stock.

I am unaware of any practical examples of contracts with exactly these provisions, though I would be grateful for suggestions from readers on this point. Formal contingencies on realized marginal cost are tricky, because customers may not be able to verify capacity utilization rates. It seems to me that the basic lesson from this investigation is the importance of stabiliaing the revenue of the firm in the appropriate way against tight conditions. The customer must be assured that the firm can't profit by underinvesting. The allocation of output when demand is strong is a subsidiary issue, and not necessarily one that must be handled by explicit marginal-cost pricing. As Dennis Carlton (1978) has noted, suppliers in intermediateproduct markets are often deeply involved in deciding upon the quantity of outplt to be delivered. Output is allocated among customers when supplies are short, not soid to the highest bi dider.

Stabilizirig unit revenue is not the only way to provide the 
right investment incentives to the firm. Total revenue could be made independent of the level of output and positively related to the amount of capital. But then the "price"--unit revenue of the firm--would be negatively related to output. Though the evidence strongly favors stable unit revenue over marginal cost, it does not go so far as to suggest declining unit revenue in good times. To put it another way, profits do decline in recessions, though not by as much as they would with marginal-cost pricing. 
5. Macroeconomic implications and conclusions

If contracts achieve output efficiency, then the price rigidity they induce is not a direct source of macro disequilibrium. In effect, output efficiency says the level of output is at the intersection of the implicit supply and demand curves for output. In this respect, the study of contracts in product markets reaches the same conclusion as the closely related study of contracts in labor markets--there are good reasons for the parties to stabilize the flow of payments from one party to the other, but no reason to expect disequilibrium or inefficiency just because the flow is stabilized. There is little doubt that disequilibrium is a major feature of the economy, but no reason to think that the price and wage rigidity associated with long-term contracts is a direct contributor to di sequilibrium.

It is probably reasonable to interpret most government price indexes as measures of the unit revenue of producers. If so, the revenue stabilization property of a contract that yields capital efficiency has important implications about the information conveyed by the price indexes. In general, unit revenue cannot be an indicator of marginal cost or of the relation between output and capital. In particular, if unit revenue is typically held perfectly stable, relative to input costs, then price indexes are deprived of much of their value in signalling the 


\begin{abstract}
current state of the economy.
If prices tracked marginal cost, and so fell during recessions and rose during booms, they would convey information in a highly usable way to agents elsewhere in the economy. For example, labor contracts are often contingent on prices, but the unresponsiveness of prices over the business cycle prevents the contingency from offsetting the parallel shifts in the demand for labor. Employment fluctuations might well be smaller (and more efficient) if prices were closer to marginal cost. In this respect, the need to stabilize revenue to provide the correct incentives for investment may indirectly contribute to macro disequilibrium as a byproduct.

Even in product markets, the stabilization of unit revenue in a transaction at an early stage of production may introduce problems at later stages. If the published price of a raw material is actually stabilized unit revenue, then the contract between a producer of a product for which the raw material is an input and a downstream purchaser cannot be made appropriately contingent on marginal cost.
\end{abstract}


Fieferences

James C. Bonbright, Frinciples of Fublic Utility Rates (New York: Columbia University Fress), 1961

Dennis Carlton, "Contracts, Frice Rigidity, and Market Equilibrium," Journal of Folitical Economy, vol. 87, pp. 10j41062 , October 1979

Lorne Carmichael, "The Agent-Agents Froblem: Fayment by Relative Output," Journal of Labor Economics, vol. 1, pp. 50-65, 1983

Robert Crandal1, The Steel Industry in Recurrent Crisis (Washington DC: The Brookings Institution), 1981

Jacques H. Dreze, "Some Fostwar Contributions of French Economists to Theory and Fublic Folicy," American Economic Review, vol. 54, June 1964 supplement, pp. 1-64

Otto Eckstein (ed.), The Econometrics of Frice Determination Conference (Washington, DC: Board of Governors of the Federal Feserve System), 1972

Fobert J. Gordon, "The Impact of Aggregate Demand on Frices," Erookings Fapers on Economic Activity, 2:1975, pp. 613-662

Jerry Green and Jean-Jacques Laffont, Incentives in Fublic Decision Making (Amsterdam: North-Holland Fublishing), 1979

Robert E. Hall and David M. Lilien, "Efficient Wage Eargains under Uncertain Supply and Demand," American Economic Review, vol. 69, pp. 868-879, December 1979

Fobert E. Hall, "Employment Fluctuations and Wage Figidity:" Erookings Fapers on Economic Activity 1:1980, pp. 91-124

Alfred E. Kahn, The Economics of Regulation: Frinciples and Institutions, Volume 1: Economic Frinciples (New York: John Wiley and Sons), 1970

Eenjamin klein, Fobert 6. Crawford, and Armen Alchian, "Vertical Integration, Appropriable Rents, and the Competitive Contracting Frocess," Jolirnal of Law and Economics, vol. 21, pp. 297-326, Dctober $19 \overline{78}$

Arthur M. Okun, "Inflation: Its Mechanics and Welfare Costs," Erootings Fapers on Economic Activity $2: 1975$, pp. 351-390 
, Prices and Quantities: A Macroeconomic Analysis, Brookings Institution, Washington, 1981

Alan A. Walters, The Economics of Foad User Charges, International Bank for Feconstruction and Development, Wor $1 d$ Bank Staff, Occasional Papers No. 5, Washington, DC, 1968

Martin Weitzman, "Toward a Theory of Contract Types," Mimeo, Department of Economics, Massachusetts Institute of Technology, October 1981. 
Appendix. Proofs of theorems.

Theorems 1 and 2 follow immediately from the assumptions of strict concavity, differentiability, and saturation.

Theorem 3. A contract with revenue formula $R(Q, k, w, r)$ provides capital efficiency only if

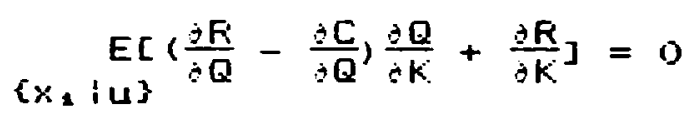

Further, if a formula satisfies this condition for $u=1$ and all $\mathrm{w}$ and $r$, it satisfies it for all $u, w$, and $r$.

\section{Proof:}

The first-order condition for maximum profit is

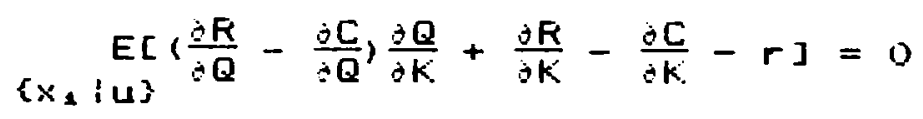

At the efficient capital stock,

$$
E\left[-\frac{\partial C}{\partial K}-r\right]=0 \text {, }
$$

so, at the efficient stock with the first-order condition satisfied as well,

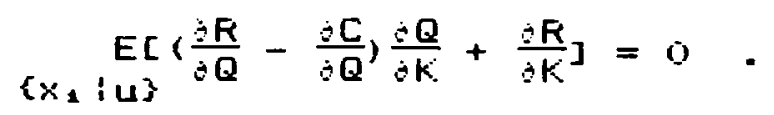


Next, let $\pi$ be expected profit:

$$
\pi(k, u, w, r)=E[F(Q, k, w, r)-C(q, k, w)-r K]
$$

The next step is to show that $\pi$ is homogeneous of degree zero in $K$ and $u$, that is,

$$
\pi(k, u, w, r)=u \pi(k i u, 1, w, r)
$$

Now,

$$
\pi=i[K(Q(k, w, x), k, w, r)-C(Q(k, w, x), k, w)-r k] g(x / u) / u d u
$$

Let $x^{\prime}=x / u$. Then

$$
\pi=\int\left[K\left(Q\left(k, w, u x^{\prime}\right), k, w, r\right)-C\left(Q\left(k, w, u x^{\prime}\right), k, w\right)-r k\right] g\left(x^{\prime}\right) d x
$$

From the first-degree homogeneity of $R$ in $Q$ and $k$, and the firstdegree homogeneity of $C$ in $Q$ and $K$,

$$
\begin{gathered}
\left.\pi=u\left[f\left(Q(Q) / u, w, x^{\prime}\right), k / u, w, r\right)-C\left(Q\left(k / u, w, x^{\prime}\right), k / u, w\right)-r k / u\right] g(x) d x \\
=u \pi(k / u, 1, w, r),
\end{gathered}
$$

as assertied.

The maximizing K plainiy has the form

$$
k(u, w, r)=u k(w, r) \quad \text {. }
$$

Then the zero-degree homogeneity of ot/okimpiies that if it equals zero at the efficient $k$ for $u=1$, it equals zero at the efficient $f$ for any value of $u$. 
Theorem 4. Under marginal-cost pricing, expected profit is a strictly decreasing function of the capital stock, at the efficient capital stock.

\section{Froof:}

Let $p$ be the marginal-cost price:

$$
p(k, w, x)=\frac{\partial C}{\Delta Q}(Q(k, w, x), K, w)
$$

Then expected profit is

$$
\pi(k, u, w, r)=E[P(k, w, x) Q(k, w, x)-C(Q, k, w)-r k]
$$

The derivative of expected profit with respect to $k$ is

$$
\frac{\partial T}{\partial K}=E\left[Q \frac{\partial D}{\partial K}+\left(p-\frac{\partial C}{\partial Q}\right) \frac{\partial Q}{\partial k}-\frac{\partial C}{\partial k}-r\right]
$$

The middle term vanishes because $p=\frac{a C}{i Q^{\circ}}$ At the efficient k,

$$
E\left(-\frac{\partial C}{\partial K}-r\right)=0
$$

Thus,

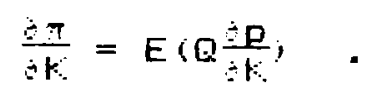

It remains to show that a larger capitai stoct always brings a lower price: 


$$
\frac{\partial D}{\partial K}<O \quad
$$

Now

$$
P \cdot=\frac{\partial C}{\partial Q}(Q, K, \omega)
$$

so

$$
\frac{\partial P}{\partial K}=\frac{\partial^{2} C \partial Q}{\partial Q^{2} \partial K}+\frac{\partial^{2} C}{\partial Q \partial K}
$$

From constant returns, $\frac{\partial^{2} C}{\partial Q^{2}}>0$ and $\frac{\partial^{2} C}{\partial Q \partial K}<0$. The next step is to look at the sign of $\frac{\partial Q}{\partial k}$. For each $i$, output efficiency requires

$$
\frac{\partial V_{1}}{\partial q_{1}}\left(q_{1}\left(k, w, x_{1}\right), x_{1}\right)=p(k, w, x),
$$

so

$$
\frac{\partial 2 V_{1}}{\partial q_{1}{ }^{2}} \frac{\partial q_{1}}{\partial K}=\frac{\partial P}{\partial K}
$$

Now $\frac{\partial 2 V_{1}}{\partial q_{1}}<0$, so $\frac{\partial q_{1}}{\partial K}$ has the opposite sign of $\frac{\partial P}{\partial k}$. Since

$$
\frac{\partial Q}{\partial K_{1}}=\Sigma \frac{\partial Q_{1}}{\partial K^{\prime}}
$$

$\frac{\partial Q}{\partial K}$ has the opposite sign of $\frac{\partial P}{\partial K}$. Suppose $\frac{\partial P}{\partial K}=0$. Then $\frac{\partial Q}{\partial K} \varrho 0$, and the right hand side of (*) is strictly negative, a contradiction. Therefore $\frac{\partial P}{\partial K}<0$. Finally, as a result, $\frac{\partial \pi}{\partial k}<0$, as asserted. 
Theorem 5. A standardized contract is output-efficient for a smail purchaser if and only if it can be written in the form

$$
\begin{aligned}
& A\left(q_{1}, Q, K, w, r\right)+5, B(Q, K, w, r)= \\
& \left(q_{1}-s_{1} Q\right) \frac{\partial C}{j Q}+s_{1} K(Q, K, w, r)
\end{aligned}
$$

Proof:

I. Sufficiency is obvious: $\frac{\partial A}{\partial Q_{1}}=\frac{\partial C}{\partial Q}$

I I. Necessity:

Efficiency requires that the buyer pay marginal cost:

$$
\frac{\partial A}{\partial Q_{1}}=\frac{\partial C}{\partial Q} .
$$

Integrate over q. to get

$$
A\left(q_{1}, Q, k, w, r\right)=q_{1} \frac{\partial C}{\partial Q}
$$

The constant of integration is zero because the standardized contract requires $A(0,0, f, w, r)=0$. Thus the output-efficient contract has the form,

$$
q_{1} \frac{\partial C}{\partial \theta}+5, E(Q, r, w, r)
$$

Let 


$$
R(\theta, k, w, r)=B(Q, k, w, r)+Q \frac{\partial C}{\partial Q}
$$

Then

$$
\begin{aligned}
& q_{1} \frac{\partial C}{\partial Q}+s_{1} B(Q, k, w, r)= \\
& q_{1} \frac{\partial C}{\partial Q} \quad s_{1}\left[R(Q, k, w, r)-Q \frac{\partial C}{\partial Q}\right]= \\
&\left(q_{1}-s_{1}\right) \frac{\partial C}{\partial Q}+s_{1} R(Q, k, w, r),
\end{aligned}
$$

as asserted. 